\title{
Snapshots of Digital Scholarship in Zooarchaeology: Introduction to the Special Issue
}

lain McKechnie ${ }^{1,2,3^{*}}$, Sarah Whitcher Kansa ${ }^{4}$, and Steve Wolverton ${ }^{5}$

Author addresses: ${ }^{1}$ Department of Anthropology, 1218 University of Oregon, Eugene, OR 97403, USA. ${ }^{2}$ Hakai Institute, Department of Archaeology, Simon Fraser University, 8888 University Drive, Burnaby, BC V5A 1S6, Canada. ${ }^{3}$ Present address: Department of Anthropology, University of Victoria, 3800 Ring Road, Victoria, BC, V8P 5C2, Canada. ${ }^{4}$ Alexandria Archive Institute \& Open Context, 125 El Verano Way, San Francisco, CA 94127, USA. ${ }^{5}$ Department of Geography, University of North Texas, 1155 Union Circle 305279, Denton, TX 76203, USA.

"Corresponding Author: iim@uvic.ca

Received: December 15, 2015

Volume: 6(2):218-223

Published: December 18, 2015

(C) 2015 Society of Ethnobiology

"Anthropology begins with people and ends with people, but in between there is plenty of room for computers"

- A quote attributed to Claude Lévi-Strauss by Eric Wolf (1964:52).

\section{Introduction}

Digital techniques and technologies are an increasingly pervasive medium for ethnobiological and archaeological scholarship in the $21^{\text {st }}$ century. A plethora of computational tools and information technologies are constantly being developed, refined, and repurposed by anthropologically oriented researchers to better collect, assess, and advance knowledge within and beyond disciplinary boundaries. It is also the case that relatively recent digital platforms and initiatives are being abandoned at an increasing rate due to technical obsolescence or lack of funding (Law and Morgan 2014). Keeping track of these developments is key to understanding the pace and scope of digitally enabled archaeological research. With this special issue, we intend to provide a snapshot of how researchers in this sub-field are using digital tools to address a range of problems which have broader relevance in both archaeology and ethnobiology.

As famously stated in the quote above, anthropology's abiding interest in studying human relationships can usefully involve computers and this need not detract from the discipline's core subject matter (Wells 2014). Such a sensibility has broadly underwritten transformative developments in disciplinary knowledge over the past 50 years and today is well represented by several digital initiatives and approaches within the discipline of archaeology, many of which have relevance in ethnobiology. Some examples from the quickly expanding archaeological data sharing landscape include approaches to data access, aggregation, and preservation (e.g., DINAA ${ }^{1}, \mathrm{tDAR}^{2}$, $\mathrm{ADS}^{3}, \mathrm{CARD}^{4}, \mathrm{SPARC}^{5}$ ); and refinements in the application of digital methods (geometric morphometrics, 3D modeling, GIS). Many parallel initiatives undoubtedly exist in ethnobiology often on more localized community focused scales.

This special issue features the work of a diverse group of researchers employing digital techniques in zooarchaeology (a.k.a. archaeozoology). Zooarchaeology is the study of animal remains in the archaeological record (e.g., bones, teeth, shells, antlers, horns, and similar tissues, as well as biomolecular remains, such as proteins and ancient DNA). The study of these remains informs understanding of past human activities and human influenced environments. Seven papers by eighteen authors from Europe and North America showcase digital research spanning three continents that includes research on fish, mammals, and birds as well as an introspective examination of zooarchaeologists themselves. These papers emerged from a symposium at the International Council for Archaeozoology conference, which took place at the Museo de Historia Natural de San Rafael in Mendoza, Argentina in September of 2014. This gathering of the global community of zooarchaeologists offered a chance to showcase new techniques and technologies that address a variety of key research questions.

\section{Improved Data Sharing}

A prominent theme explored in this special issue is the improvement of data sharing across zooarchaeological research settings and digital platforms. While 'big-data' approaches aim to standardize large-scale datasets, archaeologists are also realizing the im- 
portance of quality and accuracy of data collected by different practitioners and the challenge of incompatible datasets (Jones and Gabe 2015). The paper by Sarah Kansa (2015) describes how zooarchaeologists variously collect and document their data (or fail to do so) and how this variation can be a major impediment to disciplinary progress as it inhibits collaboration between researchers and perpetuates information silos specific to individual projects. Most importantly, Kansa (2015) shows there is a productive solution to this conundrum that does not require imposing a single 'best' documentation system requiring a highly time consuming reanalysis. Rather, she shows how the use of "linked open data" and data editing make it possible to integrate taxonomic and taphonomic data from diverse sources without compromising the original specificity of a particular database or altering vital internal structure of an individual dataset. Such a careful cross referencing takes considerable effort, attentiveness, and quality control, but once designed, strengthens the potential for data to be scaled up for a given region. This initiative has the potential to enable comparisons between a large number of existing databases without learning project-specific code. Kansa specifically discusses an example where this was successful across a large group of independent zooarchaeologists conducting research in Turkey (Arbuckle et al. 2014). The study is part of the larger Open Context project ${ }^{6}$, which is demonstrating the benefits of designing digital systems that can reconcile a diverse range of highly specific disciplinary terminologies. In an era where researchers face a burgeoning legacy of zooarchaeological information, there is a crucial need for attentiveness to incorporating previously compiled datasets and ensuring these retain as much detail as possible. This approach has implications beyond the confines of zooarchaeology in that it is relevant for comparing similarly diverse ethnobiological data such as cultural and linguistic taxonomies of plant and animal species.

The paper by Bruce Manzano et al. (2015) employs 3D scanning and printing to produce lifesized representations of skeletal elements for two rarely identified animal species: the passenger pigeon (Ectopistes migratorius) and a fish colloquially referred to as the 'harelip sucker' (Moxostoma lacerum). As Manzano and colleagues describe, both species have considerable significance in conservation biology and environmental management but are poorly identified from zooarchaeological contexts. This is unlikely to be a result of a lack of archaeological occurrences but rather, a reflection of the rarity of skeletal specimens in comparative collections with which to identify archaeofaunal remains. Such rarity is well known for the passenger pigeon, which was a famously prodigious bird throughout North America before its extinction in the early $20^{\text {th }}$ century (Greenberg 2014). However, the harelip sucker is a less prominent species that had a similarly pervasive and ecologically important distribution in rivers and streams throughout southeastern North America. The species became extinct during the industrial and agricultural transformation of waterways in the Midwest and Southeast, likely due to increased turbidity. It is notable that the disappearance of both species coincides with habitat loss associated with the expansion of industrial agriculture. This particular research contribution represents a vital step in stimulating greater awareness of these particular species within zooarchaeology, thereby adding to a growing body of literature highlighting the merits of zooarchaeological data in historical ecology and conservation biology (e.g., Kittinger et al. 2014; Lyman and Cannon 2004; Wolverton and Lyman 2012).

\section{Improved Data Collection}

Another theme explored in this special issue is a concern with improved digital data collection in zooarchaeology. The contribution by Stella Macheridis (2015) explores the role that photogrammetry (or 3D photography) has for interpretive spatial analyses of faunal remains deposited in household contexts at Çatalhöyük, a large early argricultural settlement and UNESCO World Heritage site in Turkey. Macheridis shows how repeat photography processed through commercially available software can produce three dimensional color visualizations of specific features within an archaeological site undergoing excavation. She walks readers, step-by-step, through digital documentation producing a three-dimensional, highresolution photographic model that allows researchers to consider numerous important spatial variables during analysis. This includes the orientation of zooarchaeological remains, their spatial proximity within site features and among skeletal specimens, to integration of vertical and horizontal provenience data that can be considered in reference to other features and artifacts. Such modeling provides an effective means to reconstruct feature contexts after excavation, a time consuming process that holds important potential for taphonomy and architectural reconstruction. 
The paper by Flint Dibble (2015) details the use of bar coding software to increase the efficiency and accuracy of zooarchaeological data collection, enabling an efficient transition from field to lab to data generation. Dibble has developed a versatile data collection system that promises to make zooarchaeological data collection more efficient using a relatively inexpensive setup consisting of barcode scanners, thermal printers, standard database software (MS Access), as well as a tablet computer. Barcodes are paired with labels involving clearly typed provenience information, streamlining data entry and minimizing transcription errors. Speech recognition software and anatomical visualizations of osteological elements can further speed data entry. As a result, Dibble's data collection tool allows analysts to spend more time actually identifying bones. Despite the upfront investment required for adopting such a system, this approach reaps time saving benefits and enables more sophisticated spatial and quantitative analyses. This parallels several other initiatives in archaeology that take advantage of available technology for improved information management (e.g., Austin 2014; Fee et al. 2013; Parker and Eldridge 2014).

\section{Improving Analytical Capacity}

Perhaps because zooarchaeologists comprise a small global community, they have become adept at employing technical tools from other disciplines to improve analytical capacity in their own. This special issue boasts two distinct contributions from researchers drawing on technical tools from the medical sciences, examining the potential for 3-dimensional characterizations of skeletal elements on a microscopic level. The paper by Francesco Boschin et al. (2015) uses microCT scanning to characterize the changes to mammalian bone that occur during burning at high temperatures (above $600{ }^{\circ} \mathrm{C}$ ), while the paper by Moretti et al. (2015) investigates the cross-sectional variability in cutmarks produced by different types of stone tools.

Boschin et al.'s (2015) microCT research represents a technical advance to the long history in zooarchaeological research on burning as a taphonomic process that changes the characteristics of bone and archaeological interpretations that hinge on such observations (Lyman 1994). Numerous studies have characterized color changes in bone at various temperatures (e.g., David 1990; Shipman 1988). The work that Boschin and colleagues present uses higher resolution data to confirm previous studies on changes in bone structure associated with burning, such as recrystallization (Munro et al. 2007; Stiner et al. 1995). They use this increased resolution as an opportunity to revisit specific questions such as how to determine whether or not dark (or light) coloration of bone is due to initial burning (i.e., during the biostratinomic phase of taphonomic histories) or from staining during burial (i.e., the diagenetic phase). These types of taphonomic research problems are critical to large scale questions concerning the origin of certain forms of human behavior and are also relevant outside of archaeology in the realm of forensics (Herrmann and Bennett 1999). The authors provide imagery of the types of microstructural changes that occur with burning at different temperatures; their research represents a step forward in that it shows how a new tool can examine and distinguish the effects of both 'natural' (diagenetic) and cultural processes (e.g., active burning). These three dimensional scans have the potential to be shared online and examined further from different perspectives. Indeed, researchers are increasingly placing such 3D models online for subsequent analysis and replication (e.g., Berger, et al. 2015; Maschner, et al. 2011).

The paper by Erika Moretti et al. (2015) uses 3D microscopy to analyze experimental cut marks on animal bones and characterize how tool types, as well as the application of force that created the cut, influence the nature of cut marks on bones. Here they employ an experimental archaeology approach, using modern animal bones in order to inform the analysis of ancient cut marks on bones from a Palaeolithic archaeological site in Grotta Paglicci, Italy. The authors produced cut marks on modern animal bones with various stone tools; by analyzing the marks with a 3D digital microscope, they were able to make a highly detailed comparison of metrics and profile data on the micro-morphology of the cut marks. This work reveals analytical power of such microscopic analyses, enabling precise quantification of extremely small mark dimensions and numerous cross sectional profiles within a single cut mark. Their results indicate that this approach is especially useful for distinguishing between different lithic tool types; however, it is more difficult to determine the type of motion used to make the cuts and whether the cuts were made on fresh, boiled, or dry bone. This work demonstrates the promise of combining experimental zooarchaeology with 3D microscopic analysis and raises numerous other avenues for future research projects utilizing this technology. 


\section{Improving Understanding of Disciplinary Practitioners}

Zooarchaeology, indeed archaeology, ethnobiology, and scholarly research in general, has long explored the changing demographics of science and academia (e.g., Bardolph 2014; Wolverton et al. 2015; Wyndham et al. 2011). Clearly the demographic profile of zooarchaeology is expanding and changing, which is coincident with shifting gender representation in graduate programs in anthropology and archaeology (e.g., American Anthropological Association 2015; Lazar et al. 2014). Suzanne Pilaar Birch (2015) provides a detailed analysis of the current state of zooarchaeology, whose sub-disciplinary demographics have not been thoroughly considered since the 1990s (Gifford-Gonzalez 1993, 1994; Zeder 1997). Further, due to important improvements in digital survey technology, Pilaar Birch was able to solicit the survey globally, while previous efforts concentrated on the US and Canada. Some important trends elucidated in Birch's (2015) study include: increased representation of women in zooarchaeology but a simultaneous association with greater numbers of women in lowerincome positions; the observation that most zooarchaeologists identify themselves as "European" or "white;" and that there are regions of the world, such as the global south, in which there appear to be few active zooarchaeologists, and alternatively other highly researched regions which have few local professionals. Thus, the professional profile of zooarchaeologists has much to accomplish in terms of achieving a fair and balanced representation, whether considered in terms of gender, ethnicity, and/or geography, despite that trends appear to be heading in that direction.

\section{Summary}

Collectively, the range of topics and technological applications explored in this special issue provides a current snapshot into the disciplinary interests of zooarchaeologists with respect to new digital technology. While it by no means represents a comprehensive perspective, it reveals some of the breadth of what is a very diverse and rapidly changing scholarly landscape. We are grateful to have papers in this symposium published in the Society of Ethnobiology's journal Ethnobiology Letters, which has a broad mandate and readership and meets gold open access standards. With its focus on understanding humanenvironment relationships, the Society for Ethnobiology is well placed to showcase a broad range of developments that bridge studies of plants, animals and people's concepts and uses of each. All forms of ethnobiological scholarship face challenges in organizing and comparing datasets where information limits communication across fields and perspectives. While it is difficult to keep up with developments in respective subfields in anthropology and biology, cooperation between aligned societies, such as the Society of Ethnobiology and the International Council for Archaeozoology, recognize the spirit of furthering and enriching interdisciplinary dialogue about human conditions past and present.

\section{Acknowledgements}

We thank the individual contributors for their patience and hard work on their submissions. We are grateful to have had the support of the 2014 ICAZ organizing committee in Argentina, particularly Maria Gutiérrez, Gustavo Neme, and Luis Borrero as well the Society of Ethnobiology for supporting the publication of this special issue in Ethnobiology Letters. We further thank the many anonymous reviewers and original contributors and conference participants who energized the poster session.

\section{References Cited}

American Anthropological Association. 2015. 20152016 AnthroGuide: A print directory of anthropological programs and professionals. American Anthropological Association, Arlington, VA.

Arbuckle, B. S., S. W. Kansa, E. Kansa, D. Orton, C. Çakırlar, L. Gourichon, L. Atici, A. Galik, A. Marciniak, J. Mulville, H. Buitenhuis, D. Carruthers, B. D. Cupere, A. Demirergi, S. Frame, D. Helmer, L. Martin, J. Peters, N. Pöllath, K. Pawłowska, N. Russell, K. Twiss, and D. Würtenberger. 2014. Data Sharing Reveals Complexity in the Westward Spread of Domestic Animals across Neolithic Turkey. PLoS One 9:e99845.

Austin, A. 2014. Mobilizing Archaeologists: Increasing the Quantity and Quality of Data Collected in the Field with Mobile Technology. Advances in Archaeological Practice 2:13-23.

Bardolph, D. 2014. A Critical Evaluation of Recent Gendered Publishing Trends in American Archaeology. American Antiquity 79:522-540.

Berger, L. R., J. Hawks, D. J. de Ruiter, S. E. Churchill, P. Schmid, L. K. Delezene, T. L. Kivell, H. M. Garvin, S. A. Williams, J. M. DeSilva, M. M. Skinner, C. M. Musiba, N. Cameron, T. W. Holliday, 
W. Harcourt-Smith, R. R. Ackermann, M. Bastir, B. Bogin, D. Bolter, J. Brophy, Z. D. Cofran, K. A. Congdon, A. S. Deane, M. Dembo, M. Drapeau, M. C. Elliott, E. M. Feuerriegel, D. Garcia-Martinez, D. J. Green, A. Gurtov, J. D. Irish, A. Kruger, M. F. Laird, D. Marchi, M. R. Meyer, S. Nalla, E. W. Negash, C. M. Orr, D. Radovcic, L. Schroeder, J. E. Scott, Z. Throckmorton, M. W. Tocheri, C.

VanSickle, C. S. Walker, P. Wei, and B. Zipfel. 2015. Homo naledi, a new species of the genus Homo from the Dinaledi Chamber, South Africa. eLife 4:e09560.

Boschin, F., C. Zanolli, F. Bernardini, F. Princivalle, C. Tuniz. 2015. A Look from the Inside: MicroCT Analysis of Burned Bones. Ethnobiology Letters 6:4149. Doi: 10.14237/ebl.6.1.2015.365

Chaput, M. A., B. Kriesche, M. Betts, A. Martindale, R. Kulik, V. Schmidt, and K. Gajewski. 2015. Spatiotemporal distribution of Holocene populations in North America. Proceedings of the National Academy of Sciences, USA 112:12127-12132.

David, B. 1990. How Was This Bone Burnt? In Problem Solving in Taphonomy, edited by S. Solomon, I. Davidson and D. Watson, pp. 65-79. Anthropology Museum, University of Queensland, St. Lucia, Queensland.

Dibble, F. W. 2015. Data Collection in Zooarchaeology: Incorporating Touch-Screen, Speech-

Recognition, Barcodes, and GIS. Ethnobiology Letters 6:32-40. Doi: 10.14237/ebl.6.1.2015.393.

Fee, S. B., D. K. Pettegrew, and W. R. Caraher. 2013. Taking Mobile Computing to the Field. Near Eastern Archaeology 76:50-55.

Gifford-Gonzalez, D. P. 1993. Report on the Zooarchaeology Practitioner Survey. Zooarchaeology Research News 12:3-15.

Gifford-Gonzalez, D. P. 1994. Women in Zooarchaeology. Archaeological Papers of the American Anthropological Association 5:155-171.

Greenberg, J. 2014. A Feathered River Across the Sky: The Passenger Pigeon's Flight to Extinction. Bloomsbury, New York.

Herrmann, N. P. and J. L. Bennett. 1999. The Differentiation of Traumatic and Heat-related Fractures in Burned Bone. Journal of Forensic Sciences 44:461-469.
Jones, E. L. and Caroline Gabe. 2015. The Promise and Peril of Older Collections: Meta-Analyses and the Zooarchaeology of Late Prehistoric/Early Historic New Mexico. Open Quaternary 1, p.Art. 6. Doi: http://doi.org/10.5334/oq.ag.

Kansa, S. W. 2015. Using Linked Open Data to Improve Data Reuse in Zooarchaeology. Ethnobiology Letters 6:7-14. Doi: 10.14237/ebl.6.1.2015.467.

Kittinger, J N., L. McClenachan, K. B. Gedan, and L. K. Blight, eds. 2014. Marine Historical Ecology in Conservation: Applying the Past to Manage for the Future. University of California, Berkeley.

Law, M. and C. Morgan. 2014. The Archaeology of Digital Abandonment: Online Sustainability and Archaeological Sites. Present Pasts 6, p.Art. 2. Doi: http://doi.org/10.5334/pp.58.

Lazar, I., T. Kompare, H. van Londen, and T. Schenk. 2014. The Archaeologist of the Future is Likely to be a Woman: Age and Gender Patterns in European Archaeology. Archaeologies 10:257-280.

Lyman, R. L. 1994. Vertebrate Taphonomy. Cambridge University Press, Cambridge.

Lyman, R. L. and K. P. Cannon, eds. 2004. Zooarchaeology and Conservation Biology. University of Utah Press, Salt Lake City.

Macheridis, S. 2015. Image-Based 3D Modeling as a Documentation Method for Zooarchaeological Remains in Waste-Related Contexts. Ethnobiology Letters 6:25-31. Doi: 10.14237/ebl.6.1.2015.342.

Manzano, B. L., B. K. Means, C. T. Begley, and M. Zechini. 2015. Using Digital 3D Scanning to Create "Artifictions" of the Passenger Pigeon and Harelip Sucker, Two Extinct Species in Eastern North America: The Future Examines the Past. Ethnobiology Letters 6:15-24. Doi: 10.14237/ebl.6.1.2015.368.

Maschner, H. D. G., M. W. Betts, and C. D. Schou. 2011. Virtual Zooarchaeology of the Arctic Project (VZAP). SAA Archaeological Record 11:41-43.

Moretti, E., S. Arrighi, F. Boschin, J. Crezzini, D. Aureli, A. Ronchitelli. Using 3D Microscopy to Analyze Experimental Cut Marks on Animal Bones Produced with Different Stone Tools. Ethnobiology Letters 6:50-58. Doi: 10.14237/ebl.6.1.2015.349.

Munro, L. E., F. J. Longstaffe, and C. D. White. 2007. Burning and Boiling of Modern Deer Bone: Effects 
on Crystallinity and Oxygen Isotope Composition of Bioapatite Phosphate. Palaeogeography, Palaeoclimatology, Palaeoecology 249:90-102.

Parker, A. and M. Eldridge. 2014. Archaeology in the Third and Fourth Dimensions: A Case Study of 3D Data Collection and Analysis From Prince Rupert, BC, Canada. In 21st Century Archaeology Concepts, methods and tools: Proceedings of the 42nd Annual Conference on Computer Applications and Quantitative Methods in Archaeology, edited by F. Giligny, F. Djindjian, L. Costa, P. Moscati and S. Robert, pp. 115-122. Archaeopress, Oxford.

Pilaar Birch, S. E. 2015. Diversity and Demographics of Zooarchaeologists: Results from a Digital Survery. Ethnobiology Letters 6:59-67. Doi: 10.14237/ ebl.6.1.2015.469.

Richards, J., S. Jeffrey, S. Waller, F. Ciravegna, S. Chapman, and Z. Zhang. 2011. The Archaeology Data Service and the Archaeotools project: faceted classification and natural language processing. In Archaeology 2.0: New Approaches to Communication and Collaboration, edited by E. C. Kansa, S. W. Kansa, and E. Watrall, pp. 31-56. Costen Institute, University of California Los Angeles, Los Angeles.

Shipman, P. 1988. Actualistic Studies of Animal Resources and Hominid Activities. In Scanning Electron Microscopy in Archaeology, edited by S. L. Olsen, pp. 261-285. International Series. vol. 452. British Archaeological Reports, Oxford.

Spielmann, K. A. and K. W. Kintigh. 2011. The Digital Archaeological Record: the Potentials of Archaeozoological Data Integration Through TDAR. SAA Archaeological Record 11:22-25.

Stiner, M. C., S. Kuhn, S. Weiner, and O. Bar-Yosef. 1995. Differential Burning, Recrystallization, and Fragmentation of Archaeological Bone. Journal of Archaeological Science 22:223-237.

Wells, J. J. 2014. Keep Calm and Remain Human: How We Have Always Been Cyborgs and Theories on the Technological Present of Anthropology. Reviews in Antbropology 43:5-34.

Wells, J. J., E. C. Kansa, S. W. Kansa, S. J. Yerka, D. G. Anderson, Thaddeus G. Bissett, Kelsey Noack Myers and R. Carl DeMuth. 2014. Web-Based Discovery and Integration of Archaeological Historic Properties Inventory Data: The Digital
Index of North American Archaeology (DINAA). Literary and Linguistic Computing 29:349-360.

Wolf, E. R. 1964. Anthropology. Prentice-Hall, Englewood Cliffs.

Wolverton, A., L. Nagaoka, and M. Wolverton. 2015. Breaking In: Women's Accounts of How Choices Shape STEM Careers. Stylus Press, Sterling, VA.

Wolverton, S. and R. Lee Lyman, eds. 2012. Conservation Biology and Applied Zooarchaeology. University of Arizona Press, Tucson.

Wyndham, F. S., D. Lepofsky, and S. Tiffany. 2011. Taking Stock in Ethnobiology: Where Do We Come From? What Are We? Where Are We Going? Journal of Ethnobiology 31:110-127.

Zeder, M. A. 1997. The American Archaeologist: A Profile. AltaMira Press, Walnut Creek.

\section{Notes}

${ }^{1}$ Digital Index of North American Archaeology http://alexandriaarchive.org/projects/dinaa/ (Wells, et al. 2014)

${ }^{2}$ The Digital Archaeological Record http:// core.tdar.org (Spielmann and Kintigh 2011)

3The Archaeology Data Service http:// archaeologydataservice.ac.uk (Richards, et al. 2011)

${ }^{4}$ Canadian Archaeological Radiocarbon Database http://www.canadianarchaeology.ca (Chaput, et al. 2015)

5Spatial Archaeometry Research Collaborations http://sparc.cast.uark.edu

${ }^{6}$ www.OpenContext.org

\section{Biosketches}

lain McKechnie is a SSHRC postdoctoral fellow and Hakai Institute Scholar whose zooarchaeological research focuses on the Pacific Northwest Coast. He is an incoming assistant professor in the Department of Anthropology at the University of Victoria.

Sarah Whitcher Kansa directs the non-profit Alexandria Archive Institute, working with researchers to publish open access data with Open Context.

Steve Wolverton is an archaeologist and ecologist in the Department of Geography at the University of North Texas. He is one of the founding editors of Ethnobiology Letters, and his research focuses on the intersections between zooarchaeology, ethnobiology, and conservation biology. 